\title{
Experimental Study on Anchoring Behavior of Non-Persistent Jointed Rock Mass
}

\author{
Chi Luo ${ }^{1,2, *}$, Xin'an Yang ${ }^{1,2}$, Hao Wang ${ }^{1,2}$, Mingjie Ma ${ }^{1,2}$ and Jianyi Geng ${ }^{1,2}$ \\ ${ }^{1}$ Key Laboratory of Road and Traffic Engineering of the Ministry of Education,Tongji University, Shanghai 201804, China \\ ${ }^{2}$ College of Transportation Engineering, Tongji University, Shanghai 201804, China
}

Received 27 December 2019; Accepted 14 March 2020

\begin{abstract}
The jointed rock mass is a multi-crack body, which is cut by discontinuities such as joints and faults. These joints and faults destroy the integrity and continuity of rock mass and reduce the mechanical behavior of rock mass. The rock bolting is a suitable way to reinforce the jointed rock mass. By transferring tension and shear force, the rock bolting can make best use of the strength and stability of rock mass and restrict the deformation of rock mass. In this study, the specimens containing pre-set non-persistent joints were made with granite as prototype. A series of uniaxial compression tests of the reinforced jointed specimens were conducted by rock bolts with various inclinations. The relationships among the stress-strain, anchoring force, bolt strain, bolt inclination were studied, and the change rules of the parameters of the specimens and bolt with crack evolution during compression were analyzed. Results show that the peak strength and the equivalent elastic modulus of the anchored specimens with multiple non-persistent joints first increase and then decrease with the bolt inclination increasing. The optimal anchorage angle is about $65^{\circ}$. The anchoring force is relatively large when the angle between the rock bolt and the minimum principal stress surface is small. There is a strong internal correlation among the stress, anchoring force, bolt strain and crack evolution of the jointed specimens. The obtained conclusions in this study can provide a reference to the similar engineering practice.
\end{abstract}

Key word: Jointed rock mass, Rock bolt, Anchoring angle, Non-persistent joint, Uniaxial compression test

\section{Introduction}

The jointed rock mass is a multi-crack body, which is cut by discontinuities such as joints and faults. These joints and faults destroy the integrity and continuity of rock mass and reduce the mechanical behavior of rock mass. Due to the existence of joints, the strength of rock mass with high original rock strength is also greatly reduced [1-2]. According to the scale effect of the research problem, the joints in the rock mass can be divided into two types: persistent type and non-persistent type. The crack evolution of joints is an important problem in non-persistent jointed rock mass [3-4].

In order to maintain the stability of jointed rock mass, it is necessary to adopt various measures to reinforce the rock mass, and the rock bolting is one of the suitable reinforcement methods, which is widely used in the rock mass reinforcement measures of traffic tunnels, roadbed slopes, mining caverns and other buildings. The rock bolts are buried in the rock mass, and make best use of the strength and stability of rock mass and restrict the deformation of rock mass by transferring tension and shear force [5-7].

The deformation of rock mass is often controlled by joints in rock mass, and the failure of rock mass also originates from the crack evolution under load effect. Therefore, it is very important to study the mechanical behavior of bolt in anchored jointed rock mass, such as anchoring angle, anchoring force, bolt stress and strain, for improving the anchorage effect of jointed rock mass,

*E-mail address: luochill@163.com

ISSN: $1791-2377 @ 2020$ School of Science, IHU. All rights reserved.

doi:10.25103/jestr.132.05 deepening the understanding of the role of bolt, and guiding the geotechnical engineering practice.

\section{State of the art}

Among the mechanical parameters of bolt, the anchoring angle, that is, the angle between the bolt and the joint surface, is a very important factor affecting the anchorage effect of jointed rock mass. And many scholars have studied the optimal anchoring angle of jointed rock mass by means of model tests, numerical simulations and theoretical analyses. Ge and Liu used the direct shear test and theoretical analysis to study the influence of the bolt on the shear resistance of single persistent joint surface in anchored rock mass, and discussed the influence of anchoring angle on the shear strength of joint surface and the optimal anchoring angle [8]. Pellet and Egger studied the shear resistance of bolt by theoretical method, and obtained the allowable deformation of bolts with various anchoring angles [9]. Zhao et al. established a structural mechanical model of bolt elastic deformation and complete plastic deformation for the reinforcement of layered composite rock mass, and analyzed the influence of each characteristic angle (anchoring angle, friction angle, dilatancy angle and deflection angle) of the bolt on the mechanical properties of rock bolt [10]. Wang et al. used PFC particle element software to study the anchoring mechanism of bolt in jointed rock mass with single joint surface under shear load, and the influence of anchoring system on the macro/micro mechanical response of bolt under various anchoring angles [11]. Chen et al. established the calculation formula of bolt shear resistance of jointed rock mass on the compression side of bolt, and 
analyzed the influence of the joint dilatancy coefficient, rock strength and anchoring angle on bolt deformation [12]. Liu and $\mathrm{Li}$ put forward an improved method to predict the contribution of bolt to shear resistance of jointed rock mass based on the statically indeterminate beam model, and studied the influence of bolt diameter, rock strength, anchoring method, anchoring angle and other parameters [13].

The anchoring force at the end of bolt can reflect the current stress state of bolt in anchored rock mass in the engineering practice, and many scholars have also studied its laws and functions. Zhao et al. studied the influence of bolt axial force on the shear strength of indented structural plane by the shear test and theoretical analysis of anchored rock mass with an indented structural plane, and analyzed the effect of prestressing force of rock bolt [14]. Teng et al. studied the shear behavior and the axial force distribution of bolt by the shear test of jointed rock mass with two joints under three conditions of no-anchored, end-anchored and full-anchored specimens [15]. Wang et al. used double shear test to analyze the shear resistance of bolt in jointed rock mass, and analyzed the relationship among axial force, shear force and shear displacement of bolt [16]. Su et al. studied the anchorage effect of bolt on jointed rock mass by experiments, and analyzed the mechanism of prestressing force on the anchorage effect and the evolution process of bolt axial force [17].

The stress and strain of bolt play an important role in understanding the deformation state and failure mechanism of bolt. The main researches in this field are: Lin et al. carried out the direct shear test of rock mass with a single crack with changing the grouting states, the number of rock bolts and the anchoring angles, measured the change of bolt axial stress in the shear process by strain gauge, and studied the mechanical behavior of rock bolts under the action of external force [18]. Grasselli carried out large-scale shear test and finite element simulation of anchored rock mass with two parallel persistent joints, studied the deformation mode and mechanical response of various bolt types, and analyzed the strain law of bolt and the formation of plastic hinges of bolt [19]. Liu et al. deduced the analytical solution of stress distribution of rock bolt on the single joint plane based on the traditional calculation method of bolt stress, with consideration of the shear displacement on the joint plane, and discussed the anchorage effect of bolt under various joint plan displacements and joint plane inclinations [20]. Li et al. carried out direct shear tests on three groups of single crack jointed rock specimens with various anchoring angles and grouting strengths, and analyzed the strain, deformation and bending angles of bolts in detail [21]. Ding et al. studied the bolt stress and bolting mechanism in the process of deformation of rock mass with weak interlayer by experimental method, and it was found that the fully grouted bolts bore tensile, compressive, bending and shear stress at the same time and the stress evolution of bolt was closely related to the deformation of rock mass [22].

In conclusion, many important achievements were made in the aspects of optimal anchoring angle, anchoring force, bolt stress-strain and other mechanical properties. However, these researches were mainly focused on the simple jointed rock mass with 1 or 2 cracks and the persistent joints, and the mechanical behavior and change rules of rock bolts in jointed rock mass with multiple non-persistent cracks are relatively insufficient. In this study, the specimens containing pre-set non-persistent joints were made with granite as prototype. A series of uniaxial compression tests of the reinforced jointed specimens were conducted by rock bolts with various inclinations. The relationships among the stress-strain, anchoring force, bolt strain, bolt inclination were studied, and the change rules of the parameters of the specimens and bolt with crack evolution during compression were analyzed.

\section{Methodology}

\subsection{Test specimen}

The size of test specimen was chosen as $300 \mathrm{~mm} \times 300 \mathrm{~mm}$ $\times 300 \mathrm{~mm}$. The specimen was prefabricated with five layers of non-persistent joints which penetrated in the direction of thickness, as shown in Fig. 1. The angle $\alpha$ of those pre-set joints was $45^{\circ}$. The joint length, the length of rock bridge between adjacent joints and the spacing of joint layers were all $50 \mathrm{~mm}$. The joint overlap was zero. A rock bolt was set in the test specimen, and made of bolt model material. The main geometric parameter studied in the experiment was the change of bolt inclination $\gamma$.

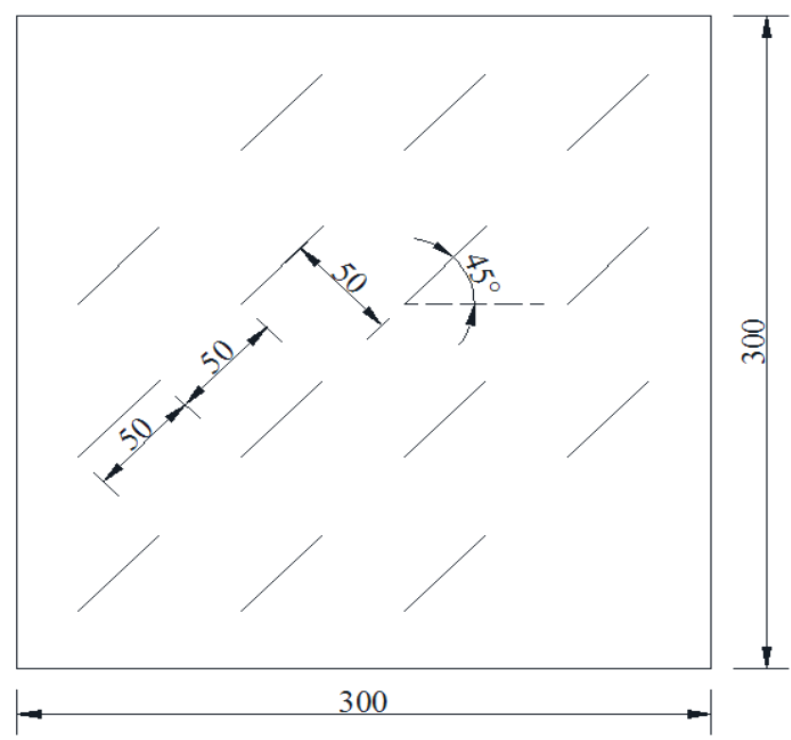

Fig. 1. Layout of non-persistent joint of test specimen (Unit: mm)

Bolt inclination $\gamma$ is defined as the angle between the rock bolt and the horizontal plane. The bolt inclination was set from $-40^{\circ}$ to $40^{\circ}$ and a test shall be carried out every $10^{\circ}$. The rock bolt was arranged in the middle of the rock mass in the fronting direction. The anchoring angle $\beta$, which is between rock bolt and joint surface, can be calculated by joint angle $\alpha$ and bolt inclination $\gamma, \beta=\alpha+\gamma$. The test scheme is shown in Fig. 2. Fig. 2(a) shows the loading direction, and Fig. 2(b) shows the arrangement of rock bolts. The ends of rock bolts were anchored by anchorage devices. In order to prevent the generation of concentrated load on test specimens, cushion blocks were installed between test specimens and anchorage devices, as shown in Fig. 2(b). Considering the effect of prestressing force in bolts in actual cases, the micro drawing instrument was used to apply prestress to the bolt. In addition, for comparative analysis, the rock mass specimen without rock bolts was tested.

\subsection{Model materials}

\subsubsection{Rock similar material}

The rock prototype was the granite. Cement, gypsum, barite and water were used to configure the rock model material 
and the proportion of each component mass should be adjusted repeatedly to meet the similarity of mechanical properties between similar material and rock prototype. Finally, it was determined that the stress similarity ratio was 45, the material bulk density similarity ratio and the poisson's ratio similarity ratio were 1 and the mass ratio of each component of similar material was cement : Gypsum : Barite : water $=0.5: 0.5: 5: 1.2$. Besides, $2 \%$ mortar additive was added into the water to ensure the fluidity of the material when pouring. The uniaxial compression strength, modulus of elasticity, poisson's ratio and density of the material were measured by the uniaxial compression test of the standard cylinder specimen. The physical and mechanical parameters of rock prototype and rock similar materials are listed in Table 1.

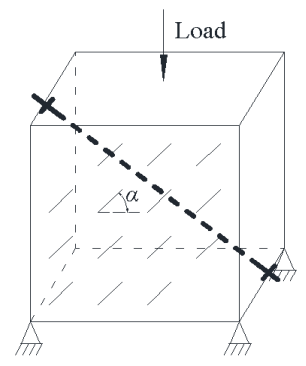
Fig. 2. Scheme of the test. (a) Loading direction

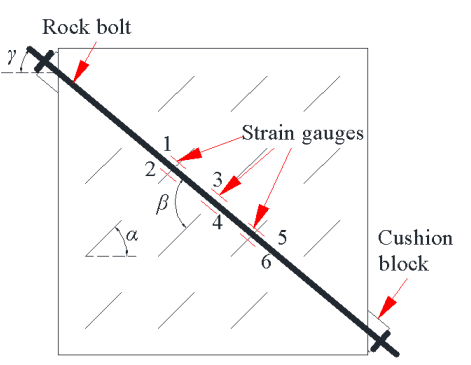

(b) Arrangement of rock bolt
Table 1. Physical and mechanical parameters of rock prototype and rock model materials

\begin{tabular}{l|l|l|l|l}
\hline \multicolumn{1}{c|}{ Type } & $\begin{array}{c}\text { Density } \\
\left(\mathbf{g} / \mathbf{c m}^{\mathbf{3}}\right)\end{array}$ & $\begin{array}{c}\text { Elasticity } \\
\text { modulus } \\
\mathbf{( G P a )}\end{array}$ & $\begin{array}{c}\text { Poisson's } \\
\text { ratio }\end{array}$ & $\begin{array}{c}\text { Compressive } \\
\text { strength } \\
\mathbf{( M P a )}\end{array}$ \\
\hline $\begin{array}{l}\text { Protolith } \\
\text { (Granite) }\end{array}$ & $2.64-2.67$ & $\begin{array}{l}39.05- \\
63.12\end{array}$ & $0.13-0.28$ & $95.22-147.56$ \\
$\begin{array}{l}\text { Similar } \\
\text { material }\end{array}$ & $2.56-2.59$ & $1.01-1.87$ & $0.16-0.19$ & $1.76-2.16$ \\
\hline
\end{tabular}

\subsubsection{Similar material for bolt}

The prototype of the rock bolt was $\phi 32 \times 6$ prestressed hollow bolt (outer diameter $32 \mathrm{~mm}$, thickness $6 \mathrm{~mm}$ ), which was made of Q345 steel. Its tensile strength was 490-620 $\mathrm{MPa}$, yield stress was $345 \mathrm{MPa}$, the calculated yield force was $169 \mathrm{kN}$, and the design value of prestressing force was $100 \mathrm{kN}$. The disposing spacing of rock bolts was $1.2 \mathrm{~m} \times 0.8$ $\mathrm{m}$ in the plane perpendicular to the bolts when using to strengthen the rock mass. It is very difficult to find the model bolt material which completely conforms to the similarity criterion. The maximum tension force of rock bolt was used as the main similarity index in many similar model experiments of anchored rock mass. However, the granite in this experiment was hard rock with high brittleness, while the rock bolt had certain plasticity. Thus, the bolt would still be in the yield state when the rock mass has been damaged, and it was more appropriate to use the yield tensile force of bolt as the index. Besides, the role of rock bolt was to strengthen the rock mass, and its number and spacing were equally important in the reinforcement of rock mass, which should also be reflected in the index above. Therefore, the main index of bolt similar material in this test was determined to be the stress on the range of actual reinforced rock mass by a single yielding bolt, that is, the index has the following relationship

$$
\sigma_{s}=\frac{F_{s}}{A}
$$

where, $F_{s}$ represents the yield force of a bolt. $A$ represents the reinforcement range of a bolt to the rock mass.

According to the similarity criterion, the similarity ratio of this index should also be 45 . In this test, the reinforcement range of bolt similar material was $0.3 \mathrm{~m} \times 0.3 \mathrm{~m}$, and the target yield force of bolt model material was $0.35 \mathrm{kN}$. In the same way, the design value of prestressing force in this test was $0.21 \mathrm{kN}$. Finally, according to the results of uniaxial tensile test of bolt model materials, 1060 series pure aluminum pipe with diameter of $6 \mathrm{~mm}$ and thickness of 0.65 $\mathrm{mm}$ were selected as the bolt similar material. The mechanical parameters of the bolt prototype and similar material are shown in Table 2.

\subsection{Test loading and data acquisition equipment}

The loading equipment of this test was NYL-500 Longcolumn Hydraulic Pressure Testing Machine, which was uniaxial loading, controlled by displacement with loading speed of $0.02 \mathrm{~mm} / \mathrm{s}$. The physical and mechanical parameters collected in the test were: (1) Compressive load; (2) Vertical deformation of the specimen; (3) Displacement of the specimen surface; (4) Anchoring force of the rock bolt; (5) Bolt strain.

The compressive load of the specimen and the anchoring force were measured by the pressure sensor. The vertical deformation was measured by the displacement meter. Two displacement meters were installed in the middle of the left and right side of the specimen, and the vertical deformation was determined by the average value of the two meters. The surface displacement was measured by the particle image velocimetry (PIV) technology through analyzing the video shot by the Canon 70D camera. The matpiv toolbox in MATLAB was adopted to implement the PIV technology. The bolt strain was measured by the strain gauge. The arrangements of strain gauges of each bolt inclination are shown in Fig. 3. The test data were collected by DT80G data acquisition instrument.

Table 2. Mechanical parameters of rock bolt

\begin{tabular}{|c|c|c|c|c|c|c|c|c|}
\hline Type & $\begin{array}{c}\text { Outer diameter } \\
(\mathrm{mm})\end{array}$ & $\begin{array}{c}\text { Thickness } \\
(\mathbf{m m})\end{array}$ & $\begin{array}{c}\text { Yield } \\
\text { strength } \\
\end{array}$ & $\begin{array}{c}\text { Yield force } \\
F_{S}(\mathbf{k N}) \\
\end{array}$ & $\begin{array}{c}\text { Reinforceme } \\
\text { nt range } A\end{array}$ & $\begin{array}{c}\sigma_{s} \\
(\mathbf{k P a})\end{array}$ & $\begin{array}{c}\text { Prestressing } \\
\text { force } F_{0}(\mathbf{k N})\end{array}$ & $\begin{array}{c}\sigma_{0} \\
(\mathbf{k P a}) \\
\end{array}$ \\
\hline Prototype & 32 & 6 & 345 & 169 & 0.96 & 176.04 & 100 & 104.17 \\
\hline Similar materials & 6 & 0.65 & 49.58 & 0.54 & 0.09 & 6.00 & 0.21 & 2.33 \\
\hline Similarity ratio & & & & & & 29.34 & & 44.64 \\
\hline
\end{tabular}




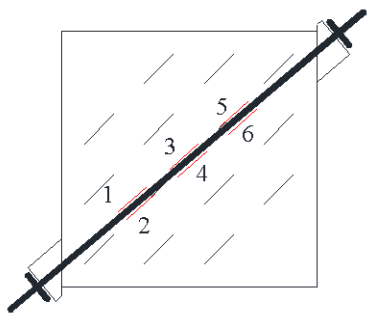

(a) $-40^{\circ}$

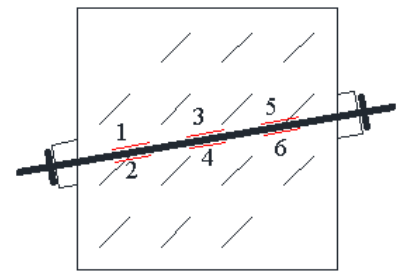

(d) $-10^{\circ}$

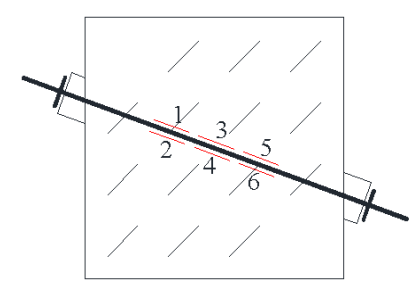

(g) $20^{\circ}$

Fig. 3. Layout of strain gauges of each bolt inclination.

\subsection{Test procedure}

\subsubsection{Manufacture of test specimens and cushion blocks}

When making the test specimens, the rock similar material was poured into the specimen mold, as shown in Fig. 4. 1.5 $\mathrm{mm}$ thick steel sheets were inserted into the groove of the upper and the lower limit plates of the mold to form open prefabricated joints. In order to ensure the compactness and flatness of the specimen, the pouring process was carried out on the vibrating table so that the material could be fully vibrated. 3 hours after pouring, pull out the steel sheets. The test specimens were demoulded after curing for 7 days and prepared for the test.

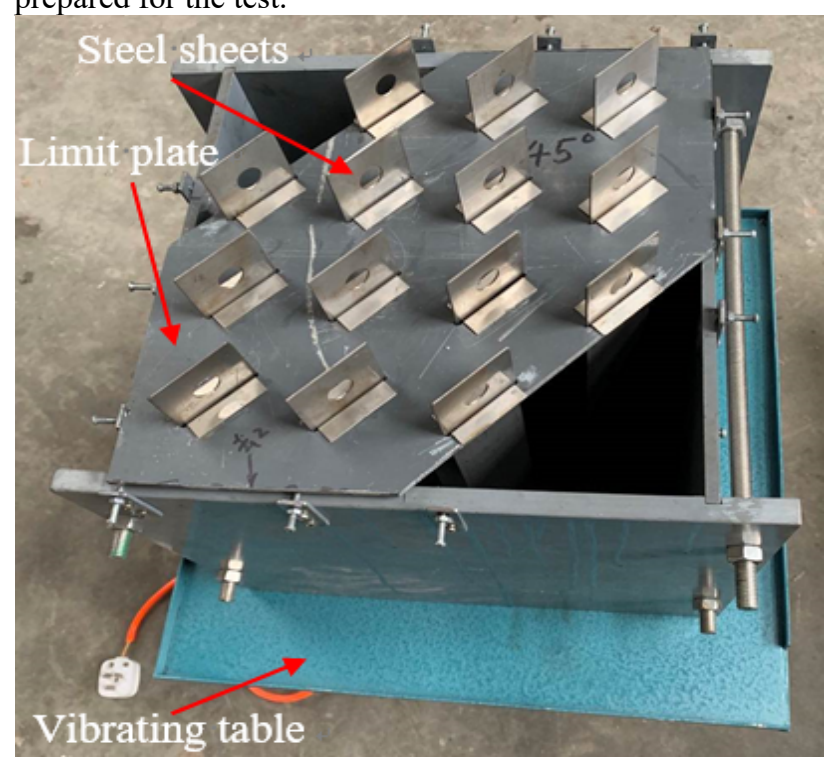

Fig. 4. Mold of test specimen.

The cushion blocks were cast with the same rock similar material as the specimen. They were two inclined blocks made of $70 \mathrm{~mm} \times 70 \mathrm{~mm} \times 70 \mathrm{~mm}$ blocks cut along the center according to the bolt inclination. Therefore, a group

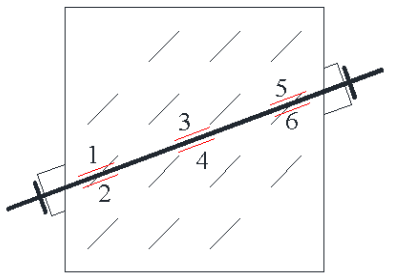

(c) $-20^{\circ}$

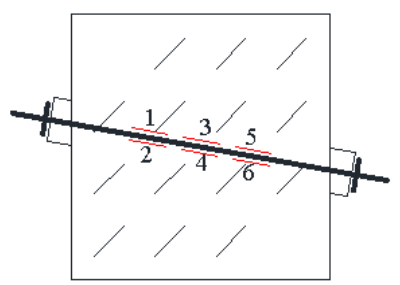

(f) $10^{\circ}$

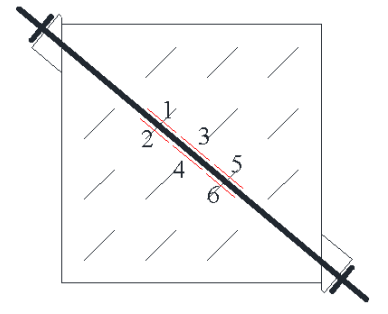

(i) $40^{\circ}$

of cushion blocks with corresponding angle should be cast for all non-zero angles. The manufacture of cushion blocks is shown in Fig. 5.

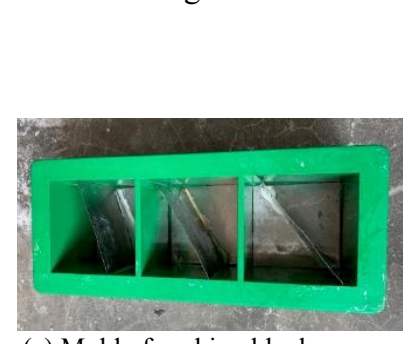

(a) Mold of cushion blocks

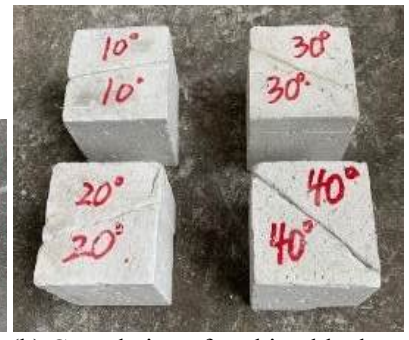

(b) Completion of cushion blocks

Fig. 5. Manufacture of cushion blocks.

\subsubsection{Anchorage preparation of test specimens}

The position of two cushion blocks and the rock bolt in each test specimen were marked. The cushion blocks onto the rock mass specimens were fixed twith $\mathrm{AB}$ glue. Then the specimen and cushion blocks were drilled with a $10 \mathrm{~mm}$ diameter drill rod to bore a hole where the bolt would pass through. It was very important to observe the position of the drill rod at any time during the drilling and correct the deviation in time. Afterwards, the bolt similar material, with strain gauges attached at selected positions on the bolt, was passed through the hole, the pressure sensor for measuring the anchoring force and the jack of the micro drawing instrument in turn. The bolt was anchored at two ends with anchorage devices. Finally, by applying $0.21 \mathrm{kN}$ prestressing force to the bolt with the micro drawing instrument, the preparation work of prestressed bolt for a test specimen was completed. The anchorage preparation of a test specimen is shown in Fig. 6.

\subsubsection{Uniaxial compression of anchored specimens}

The anchored specimen was placed in the center of the testbed. Two displacement meters were installed in the left and right side of the specimen. Then, the steel plate for 
transferring the load and the pressure sensor for measuring the compressive load were placed above the specimen in turn. Afterwards, the Canon 70D camera was erected to record the compression process in front of the test specimen. In order to ensure uniform and sufficient illumination on the surface of the specimen, an artificial light source was placed between the camera and the specimen. The displacement meters, pressure sensors and strain gauges were all connected with the DT80G data acquisition instrument, and the automatic data acquisition was started.

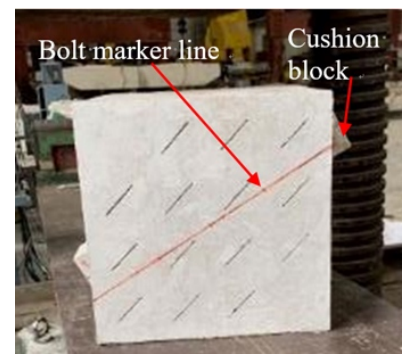

(a) Fix cushion blocks

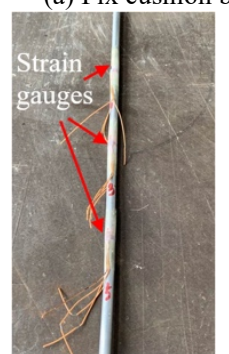

(c) Attach strain gauges

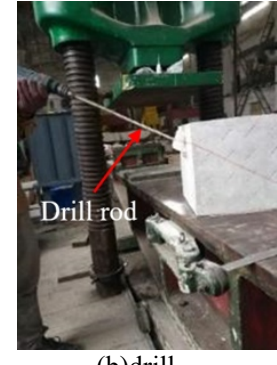
(b)drill

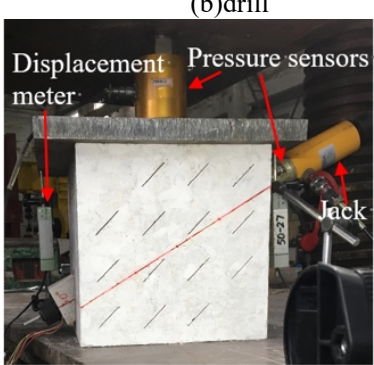

(d) Apply prestressing force
Fig. 6. Anchorage preparation of the test specimen.

The loading equipment was started and the loading speed was kept constant. When there was nonzero pressure in the pressure sensor for measuring compressive load, the digital camera started to take videos. Thus, the time in video was related to the time of the data acquisition instrument to facilitate analysis. When the specimen was compressed to a large amount of deformation or there were many falling blocks, stop loading.

\section{Results and discussion}

\subsection{Stress-strain curve of rock mass}

According to the data of compressive load and vertical deformation of the specimen in the anchoring behavior test of non-persistent jointed rock mass, the stress-strain relationship of the anchored rock mass under various bolt inclinations were obtained, as shown in Fig. 7. The peak strength of the anchored rock mass under various bolt inclinations are higher than that of the rock mass without anchorage, which indicates that the anchorage can effectively improve the strength of the jointed rock mass.

Based on this curve, the data of the peak strengths and equivalent elastic modulus of anchored rock mass under various bolt inclinations were sorted out, as shown in Fig. 8. It can be seen that the peak strength of the anchored rock mass increases first and then decreases with the increase of the bolt inclination. When the bolt inclination is $20^{\circ}$, the peak strength has a maximum value of $0.94 \mathrm{MPa}$. The anchoring angle is $65^{\circ}$, that is, the optimal anchoring angle. The rule of equivalent elastic modulus is basically the same with the peak strength, and generally increases first and then decreases with the increase of bolt inclination. The maximum equivalent elastic modulus is $0.45 \mathrm{GPa}$, just when the bolt inclination is also $20^{\circ}$

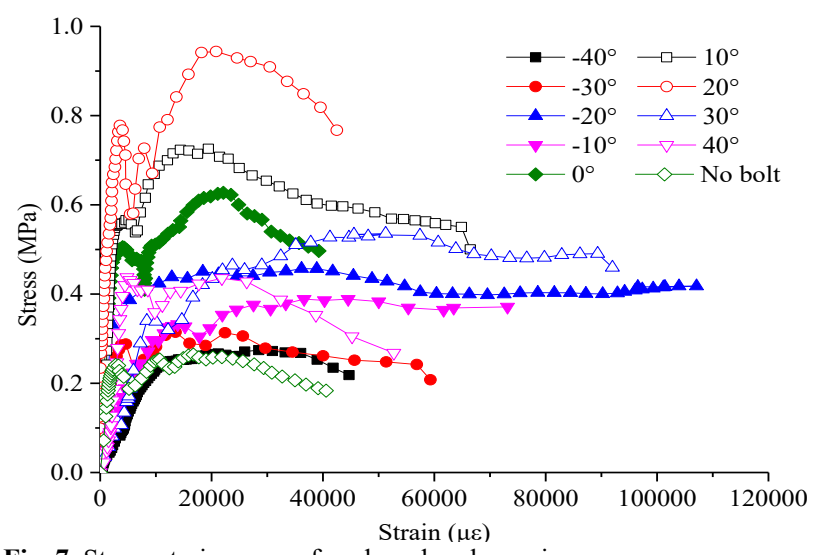

Fig. 7. Stress-strain curve of anchored rock specimen.

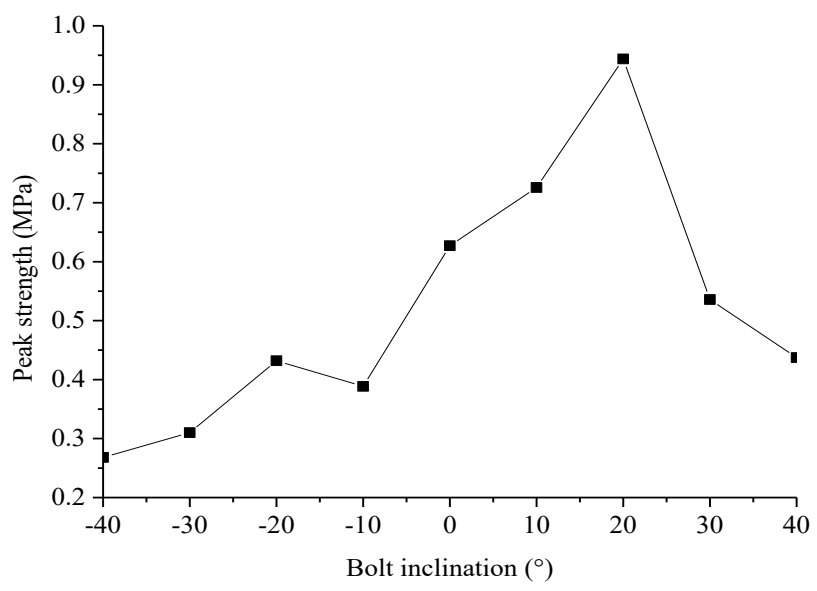

(a) Peak strengths

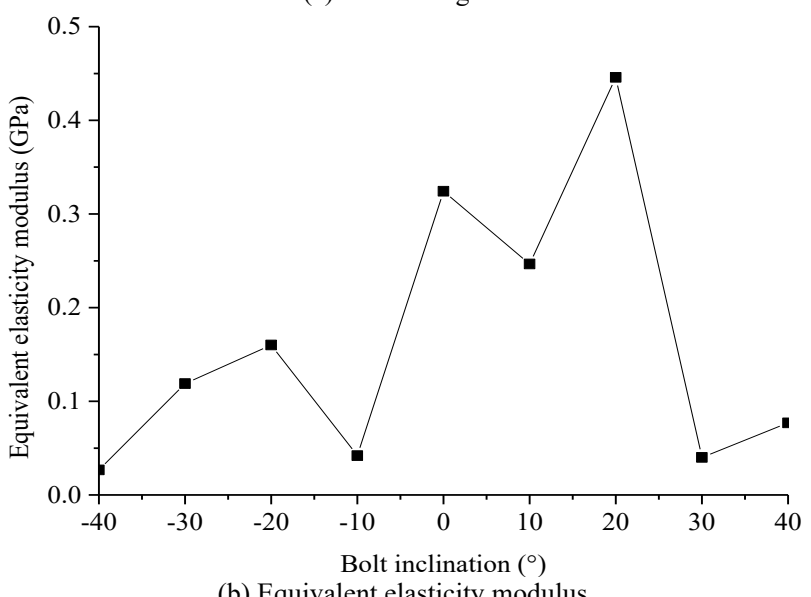

(b) Equivalent elasticity modulus

Fig. 8. The mechanical parameters variation with bolt inclination.

In this test, the optimal anchoring angle of multiple nonpersistent jointed rock mass is $65^{\circ}$, which is consistent with or similar to the $60^{\circ}$ obtained by Ge [8] in the direct shear test of a single persistent joint, the $50^{\circ}-60^{\circ}$ obtained by Zhao [10] in the layered composite rock mass, the $45-75^{\circ}$ obtained by Wang [11] with PFC simulation, and the $30^{\circ}-68^{\circ}$ calculated by Chen [12] according to the theoretical formula.

\subsection{Anchoring force}

During the compression process of the anchored rock specimen, the relationship curves between the anchoring force and the rock mass strain under various bolt inclinations 
are shown in Fig. 9. The anchoring force data with the bolt inclination of $0^{\circ}$ is abnormal, and omitted in the figure. From the relationship between the anchoring force and the strain, when the specimens have not been compressed, the anchoring force of all specimens is $0.21 \mathrm{kN}$ due to prestress. As specimens are gradually compressed, the anchoring force increases linearly with the rock mass strain, and then tends to be stable.

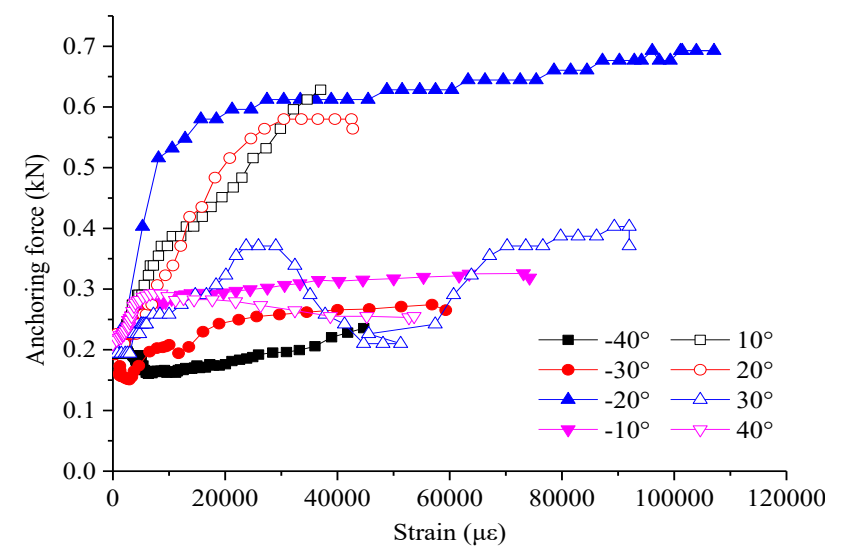

Fig. 9. The relation curve between anchoring force and rock mass strain.

In order to compare the anchoring force by various bolt inclinations, the anchoring force at the peak strength and the maximum anchoring force of specimens with various bolt inclinations were counted, as shown in Table 3. The anchoring force under the bolt inclinations between $-20^{\circ}$ and $20^{\circ}$ are significantly higher than that of other bolt inclinations when the strengths of the anchored specimens reach the peak. That is to say, the rock bolt within the angle of $\pm 20^{\circ}$ to the minimum principal stress plane (the plane perpendicular to the direction of the minimum principal stress) is easy to produce larger anchoring force. When the bolt inclination is $-20^{\circ}$, the anchoring force is large, while the peak strength is low, which shows that the anchoring force has no necessary relationship with the anchoring effect of the bolt in jointed rock mass.

Table 3. Anchoring force with various bolt inclinations

\begin{tabular}{c|c|c}
\hline $\begin{array}{c}\text { Bolt inclination } \\
\left({ }^{\circ}\right)\end{array}$ & $\begin{array}{c}\text { Anchoring force } \\
\text { at peak strength } \\
(\mathbf{k N})\end{array}$ & $\begin{array}{c}\text { Maximum } \\
\text { anchoring } \\
\text { force }(\mathbf{k N})\end{array}$ \\
\hline-40 & 0.18 & 0.24 \\
-30 & 0.19 & 0.27 \\
-20 & 0.61 & 0.69 \\
-10 & 0.31 & 0.33 \\
0 & - & - \\
10 & 0.40 & 0.68 \\
20 & 0.52 & 0.58 \\
30 & 0.21 & 0.40 \\
40 & 0.28 & 0.29 \\
\hline
\end{tabular}

\subsection{Bolt strain}

The bolt strain at the middle of the rock bolt can be calculated by taking the average value of the bolt strains at the $3^{\#}$ and the $4^{\#}$ measuring points. The relationship curves between the bolt strain and the rock mass strain under various bolt inclinations are shown in Fig. 10. It can be found that when the rock mass strain is small, the bolt strain increases linearly; when the rock mass strain further increases, there will be an obvious inflection point on the curve, and the strain value increases rapidly. The rock mass strain variables at the inflection point of the curve under various bolt inclinations are quite different: The strain inflection points of rock bolt with the inclinations of $0^{\circ}$ and $10^{\circ}$ appear relatively early; then the inflection points of $-30^{\circ}$, $10^{\circ}$ and $20^{\circ}$ appear; after that the inflection points of $-20^{\circ}$ and $30^{\circ}$ appear; strain inflection point of rock bolt of $40^{\circ}$ inclination appears last; and the strain inflection point of rock bolt of $-40^{\circ}$ inclination never appears. It can be found that the smaller the absolute value of the bolt inclination is, that is, the smaller the angle between the rock bolt and the minimum principal stress plane is, the earlier the inflection point of the curve between the bolt strain and the rock mass strain appears.

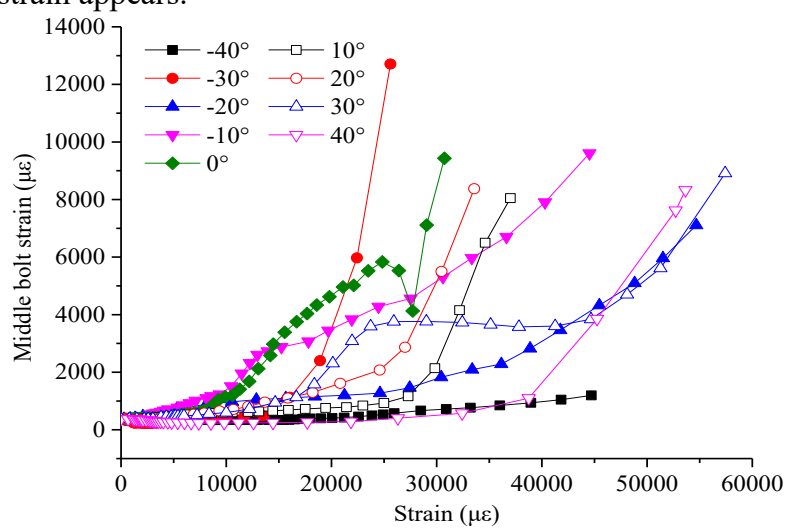

Fig. 10. The relationship curve between bolt strain in the middle of rock bolt and rock mass strain.

In the two aspects of anchoring force and bolt strain, this test has a relatively consistent conclusion on these two parameters: when the angle between the bolt and the minimum principal stress plane is small, the anchoring force will be larger and the anchor strain in the middle of the bolt increases earlier than those of large angles. It shows that the anchoring force and bolt strain may be mainly caused by the lateral deformation due to the compression of the rock mass. Therefore, the two parameters are greatly influenced by the angle between the bolt and the minimum principal stress plane, and have less relationship with the anchoring angle.

\subsection{Comprehensive analysis of crack evolution with a bolt inclination of $20^{\circ}$}

In the following, taking the anchored rock mass with a bolt inclination of $20^{\circ}$ as an example, the correlation and change rules of various factors of the anchored rock mass with rock mass strains were comprehensively investigated. Fig. 11 shows the data summary results of rock mass stress, anchoring force and bolt strain when the bolt inclination was $20^{\circ}$. Figs. 12 and 13 show the crack evolution diagram and surface displacement vector diagram with the bolt inclination of $20^{\circ}$. The displacement vector diagram was obtained by using PIV technology to analyze the rock mass surface images at different time in the video and calculate the displacement of each pixel in the images. Besides, in order to eliminate the influence of translation displacement of the specimen during the test, the displacement vector diagram took the center of the specimen as the displacement fixed point.

The initial condition of the test specimen is shown in Fig. 12(a), and the red line in the figure is marked as the bolt position in the specimen. To facilitate the analysis of crack evolution, the complete process from the beginning to complete failure is divided into three stages: the stage from the beginning to crack initiation, the stage from crack initiation to stress peak and the stage from stress peak to failure. The analysis of each stage is as follows:

(1) Stage from beginning to crack initiation $(0-4242 \mu \varepsilon)$ : With the compression of rock mass, the stress of rock mass increases gradually, and the anchoring force and bolt strain 
are basically unchanged. When the compression strain reaches $4242 \mu \varepsilon$, cracks begin to appear in the rock mass, which are mainly at rock bridges on the left joint surface as open cracks, as shown in the blue frame in Fig. 12(b). According to the surface displacement vector diagram, the left part of the cracks has a large displacement moving to the

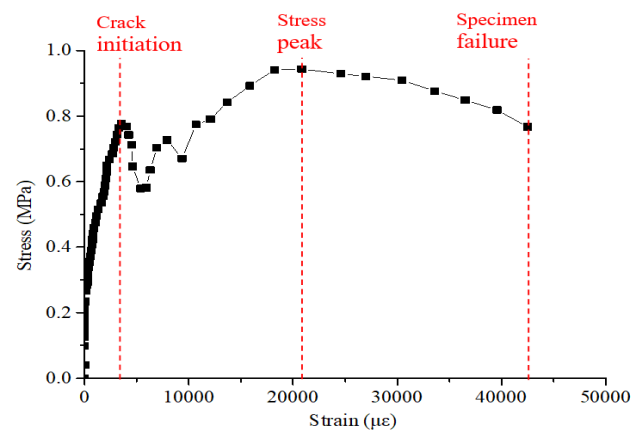

(a) Stress-strain curve of rock mass

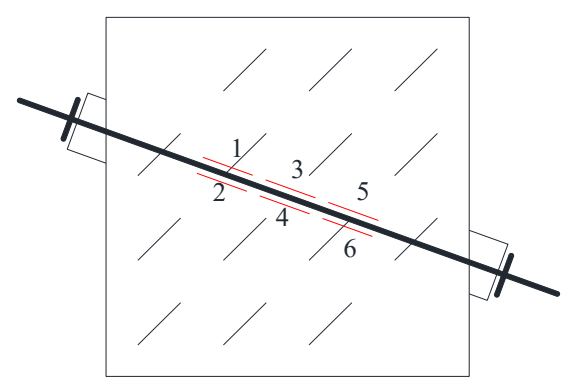

(c) Arrangement of bolt and strain gauges

Fig. 11. Summary results of test data with the bolt inclination of $20^{\circ}$.

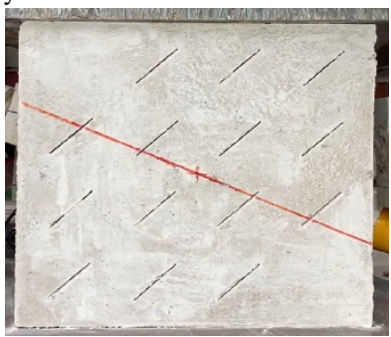

(a) $0 \mu \varepsilon$

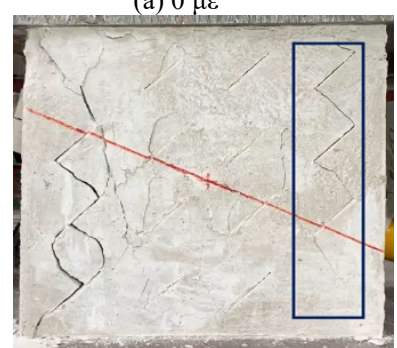

(d) $20833 \mu \varepsilon$ (Stress peak)

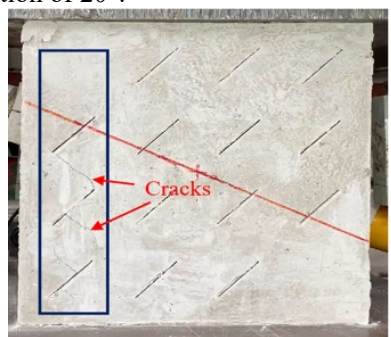

(b) $4242 \mu \varepsilon$ (Crack initiation)

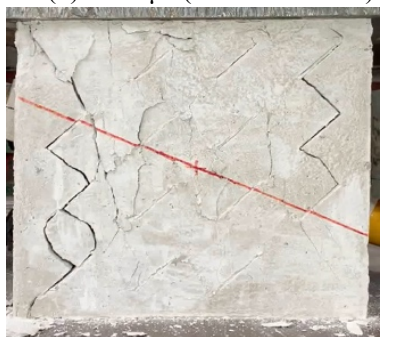

(e) $30458 \mu \varepsilon$ upper left, while the right part has a small displacement moving to the lower right. At this time, the rock mass stress reaches a small peak in the stress-strain curve, as shown in Fig. 11(a). With the further increase of compression strain, the stress of rock mass decreases, while the anchoring force increases.

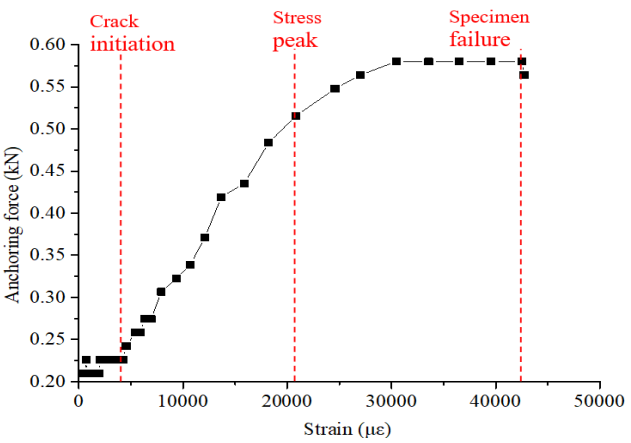

(b) Anchoring force variation with rock mass strain

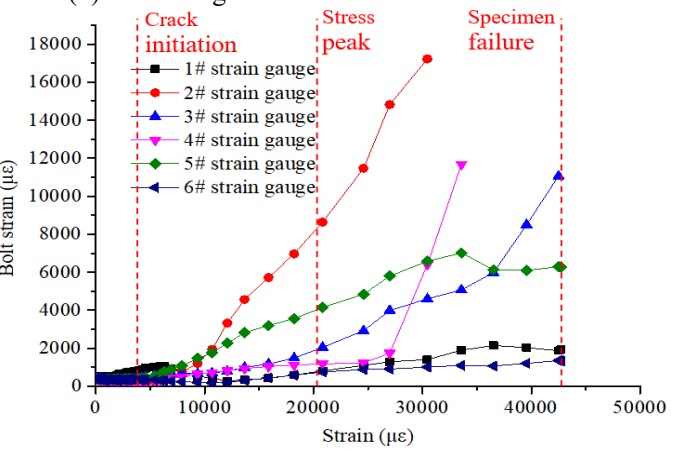

(d) Bolt strain variation with rock mass strain

Fig. 12. Crack evolution of anchored rock mass with the bolt inclination of $20^{\circ}$ under various compression strains.

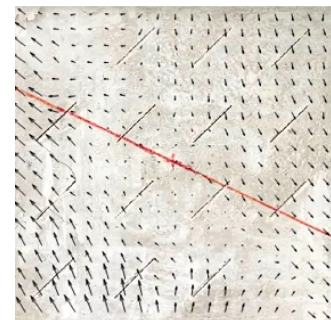

(a) $4242 \mu \varepsilon$ (Crack initiation)

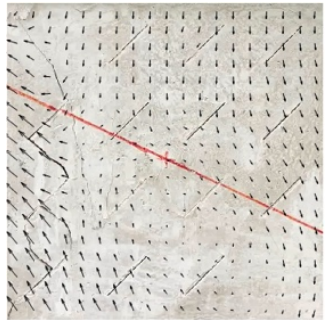

(b) $7917 \mu \varepsilon$

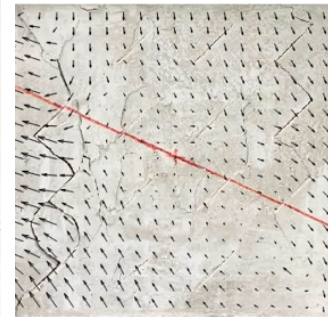

(c) $20833 \mu \varepsilon($ Stress peak)

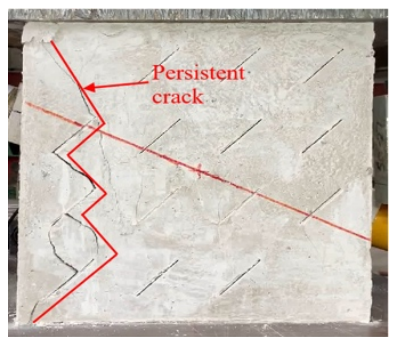

(c) $7917 \mu \varepsilon$

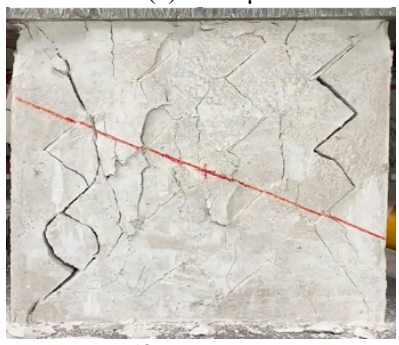

(f) $42508 \mu \varepsilon$

Fig. 13. Surface displacement vector of anchored rock mass with the bolt inclination of $20^{\circ}$ under various compression strains.

(2) Stage from crack initiation to stress peak (4242$20833 \mu \varepsilon)$ : After crack initiation, the stress of rock mass first decreases due to cracking, then increases, and forms a second small peak at $7917 \mu \varepsilon$. At this time, it can be seen from Fig. 12(c) that the original cracks expand further and form a large persistent crack running through the rock mass 
on the left side, which results in the decrease of the rock mass strength and the formation of the second small peak. During this period, the anchoring force continues to increase while the bolt strain slightly increases, but the increment is small; the displacement direction of the rock mass on the left side of the crack is still upper left.

When the strain increases from $7917 \mu \varepsilon$ to $20833 \mu \varepsilon$, where the stress of rock mass reaches the peak, the stress of rock mass and the anchoring force of rock bolt increase gradually. Open cracks begin to appear at the rock bridges of joints on the right side of rock mass, as shown in the blue frame in Fig. 12(d). The bolt strains at $2^{\#}$ and $5^{\#}$ measuring points begin to increase significantly. Compared with Fig. 11 , it can be found that the tensile strains at the $2^{\#}$ and $5^{\#}$ measuring points is large, while the strains at the $1^{\#}$ and $6^{\#}$ measuring points is always small, which indicates that the left side of the rock bolt is bent upward and the right side is bent downward at this time, and the deformation of the whole rock bolt is generally centrosymmetric. Considering the yielding bolt strain $(3000 \mu \varepsilon)$ of the bolt similar material and Grasselli's research [19] about the plastic hinges of the bolt on both sides of a single joint surface, it can be found that the plastic hinges have been formed at the $2^{\#}$ and $5^{\#}$ measuring points of the bolt. The two plastic hinges are caused by the large shear displacement of the two parallel joint surfaces.

(3) Stage from stress peak to failure $(20833-42508 \mu \varepsilon)$ : In this stage, the rock surface is further broken and uplifted, and some falling blocks appear. The rock mass displacement on the left side gradually changes from the direction of upper left to the direction of almost complete left, while the rock mass displacement on the right side is still small with the direction of lower right. The rock mass stress continues to decline. The anchoring force increases gradually to the yield force of $0.58 \mathrm{kN}$ at first, and then remains unchanged. The bolt strains at $2^{\#}$ and $5^{\#}$ measuring points continue to increase. The bolt strains at $3^{\#}$ and $4^{\#}$ increase sharply after the strain reaching $7000 \mu \varepsilon$ and $36525 \mu \varepsilon$, respectively. However, the bolt strains at $1^{\#}$ and $6^{\#}$ measuring points are still small. Obviously, due to the existence of the two plastic hinges, the $3^{\#}$ and $4^{\#}$ measuring points in the middle of the plastic hinges are subject to large tensile force, and the rock bolt in the middle of the two plastic hinges enters the yield state. The plastic hinges and the deformation of the whole bolt are still centrosymmetric.

The above analysis fully shows that there is a strong internal correlation among the crack evolution, rock mass stress, anchoring force and bolt strain of the anchored rock mass: the crack propagation can reduce the stress of rock mass, so that there will be a peak point on the stress-strain curve of anchored rock mass; the anchoring force will not increase significantly until the rock mass cracks; in the rock mass with multiple joint surfaces, the bolt at the joint surfaces can be bent and generate plastic hinges due to the slip of joint surfaces. The bolt stress-strain varies greatly among the plastic hinges.

Although the plastic hinges in this test are very similar to those in the research of Grasselli [19] (both of them have two plastic hinges, both have bolt bending at the plastic hinges and stretching between them, and both are centrosymmetric in bolt deformation), they are totally different. The Grasselli's study was aimed at a single joint surface, and the two plastic hinges on two sides of the joint surface were relatively micro-scale; while the plastic hinges in this test are produced by two or more joint surfaces, which are relatively macro-scale.

\section{Conclusion}

A series of uniaxial compression tests of the reinforced jointed specimens were conducted by rock bolts with various inclinations. The optimal anchoring angle of rock mass with non-persistent joints was studied based on the stress-strain curve of rock mass, and the change rules of anchoring force and bolt strain were studied. The bolt inclination of $20^{\circ}$ was taken as an example to analyze the change rule of anchorage parameters on the crack evolution of jointed rock mass comprehensively. The main conclusions are as follows.

(1) The peak strength and the equivalent elasticity modulus of the anchored rock mass with multiple nonpersistent joints increase first and then decrease with the bolt inclination, and the optimal anchorage angle is about $65^{\circ}$. The peak strength of the anchored rock mass are higher than that of the rock mass without anchorage, which indicates that the anchorage can effectively improve the strength of the jointed rock mass.

(2) The curve of the relationship between the anchoring force and the rock mass strain basically grows linearly first, and then tends to be stable. The anchoring force is relatively large when the angle between the bolt and the minimum principal stress plane is small. The magnitude of the anchoring force is not necessarily related to the anchoring effect of the rock bolt in jointed rock mass.

(3) The curve of bolt strain in the middle of the rock bolt tends to have an obvious inflection point with the compression of rock mass. Before the inflection point, the bolt strain changes very slowly, and after the inflection point, the bolt strain increases rapidly. The smaller the angle between rock bolt and the minimum principal stress surface is, the earlier the inflection point of the curve between bolt strain and rock mass strain appears.

(4) There is a strong internal correlation among rock mass stress, anchoring force, bolt strain and crack evolution of jointed rock mass: the crack propagation can reduce the peak point on the stress-strain curve; the anchoring force will not increase significantly until the rock mass cracks; in the rock mass with multiple joint surfaces, the bolt at the joint surfaces can be bent and generate plastic hinges due to the slip of joint surfaces, and the bolt stress-strain varies greatly among the plastic hinges.

This test is a similar model test for the rock mass with joint plane inclination of $45^{\circ}$, prototype rock as hard rock represented by granite, and anchoring method as end anchorage. In the further study, it can be considered to change the joint plane inclination, prototype rock, anchoring method and other conditions for similar tests.

\section{Acknowledgements}

This work was financially supported by the Research and Development Plan of China Railway Corporation (2017G007-A). We would like to express our sincere gratitude to the editor and anonymous reviewers for their valuable contributions to this study.

This is an Open Access article distributed under the terms of the Creative Commons Attribution License 


\section{References}

1. Jing, H. W., Yang, S. Q., Zhang, M. L., Xu, G. A., Chen, K. F., "An experimental study on anchorage strength and deformation behavior of large-scale jointed rock mass". Tunnelling and Underground Space Technology, 43, 2014, pp. 184-197.

2. Wang, S. R., Xiao, H. G., Cao, C., Zou, Z. S., Liu, X. L., "Simulation verification analysis of anchoring characteristics of transverse rib steel bar during pull-out test". Dyna, 91(5), 2016, pp. 548-553.

3. Yang, S. Q., Yin, P. F., Zhang, Y. C., Chen, M., Zhou, X. P., Jing, H. W., "Failure behavior and crack evolution mechanism of a nonpersistent jointed rock mass containing a circular hole". International Journal of Rock Mechanics and Mining Sciences, 114, 2019, pp. 101-121.

4. Ghazvinian, A., Sarfarazi, V., Schubert, W., Blumel, M., “A study of the failure mechanism of planar non-persistent open joints using PFC2D”. Rock Mechanics and Rock Engineering, 45(5), 2012, pp. 677-693.

5. Srivastava, L. P., Singh, M., "Effect of fully grouted passive bolts on joint shear strength parameters in a blocky mass". Rock Mechanics and Rock Engineering, 48(3), 2015, pp. 1197-1206.

6. Xu, H., Li, T. B., Xia, L., Zhao, J. X., Wang, D., "Shaking table tests on seismic measures of a model mountain tunnel". Tunnelling and Underground Space Technology, 60, 2016, pp. 197-209.

7. Bergamo, P., Donohue, S., Callan, D., Holland, A., McCarey, J., Brown, W., "Evaluation of full scale shear performance of tension anchor foundations: load displacement curves and failure criteria". Ocean Engineering, 131, 2017, pp. 80-94.

8. Ge, X. R., Liu, J. W., "Study on the shear resistance behavior of bolted rock joints". Chinese Journal of Geotechnical Engineering, 10(1), 1988, pp. 8-19.

9. Pellet, F., Egger, P., "Analytical model for the mechanical behaviour of bolted rock joints subjected to shearing". Rock Mechanics and Rock Engineering, 29(2), 1996, pp. 73-97.

10. Zhao, Z. H., Sun, W., Chen, S. J., Wang, W. M., Wang, Q. B., "Coupling model of jointed rock mass and rock bolt in offshore LPG underground storage". Energy Science \& Engineering, 00, 2020, pp. 1-16.

11. Wang, G., Zhang, Y. Z., Jiang, Y. J., Wang, S. G., Jing, W. J., "Macro-micro failure mechanisms and damage modeling of a bolted rock joint". Advances in Materials Science and Engineering, 2017, ID 1627103, pp. 1-15.
12. Chen, W. Q., Zhao, Y. F., Zhou, J. J., "Shear resistance theory of bolt considering nonlinear behaviour of grout reaction force". Rock and Soil Mechanics, 39(5), 2018, pp. 1662-1668.

13. Liu, C. H., Li, Y. Z., "Predicting the shear resistance contribution of passive fully grouted bolts to jointed rock". International Journal of Geomechanics, 20(2), 2020, ID 04019174, pp. 1-11.

14. Zhao, Y. F., Zhang, H. T., Nie, Y., "Study of shear capacity of jointed rock mass with prestressed anchor bolt". Advances in Civil Engineering, 2019, ID 6824543, pp. 1-10.

15. Teng, J. Y., Zhang, Y. N., Tang, J. X., Zhang, C., Li, C. L., "Experimental study on shear behavior of jointed rock mass with anchorage mode". Rock and Soil Mechanics, 38(8), 2017, pp. 2279 2285.

16. Wang, S. R., Xiao, H. G., Hagan, P., Zou, Z. S., "Mechanical behavior of fully-grouted bolt in jointed rocks subjected to double shear tests". Dyna, 92(3), 2017, pp. 314-320.

17. Su, H. J., Jing, H. W., Zhao, H. H., Yu, L. Y., Wang, Y. C., "Strength degradation and anchoring behavior of rock mass in the fault fracture zone". Environmental Earth Sciences, 76(4), 2017, pp. $1-11$

18. Lin, H., Zhu, Y. Y., Yang, J. Y., Wen, Z. J., "Anchor stress and deformation of the bolted joint under shearing. Advances in Civil Engineering, 2020, ID 3696489, pp. 1-10.

19. Grasselli, G., "3D behavior of bolted rock joints: experimental and numerical study". International Journal of Rock Mechanics and Mining Sciences, 42(1), 2005, pp. 13-24.

20. Liu, J. F., Yang, H. Q., Wen, H. J., Zhou, X. P., “Analytical model for the load transmission law of rock bolt subjected to open and sliding joint displacements". International Journal of Rock Mechanics and Mining Sciences, 100, 2017, pp. 1-9.

21. Li, Y. Z., Liu, C. H., "Experimental study on the shear behavior of fully grouted bolts". Construction and Building Materials, 223, 2019, pp. 1123-1134.

22. Ding, S. X., Jing, H. W., Chen, K. F., Xu, G. A., Meng, B., "Stress evolution and support mechanism of a bolt anchored in a rock mass with a weak interlayer". International Journal of Mining Science and Technology, 27(3), 2017, pp. 573-580. 